Pesq. Vet. Bras. 29(12):985-992, dezembro 2009

\title{
Avaliação da resposta inflamatória hematológica em cascavéis (Crotalus durissus Linnaeus, 1758) inoculadas com BCG ${ }^{1}$
}

\author{
Wellington Bandeira da Silva ${ }^{2^{*}}$, Claudio Machado ${ }^{4}$, Daphne W. Goldberg ${ }^{3}$, \\ Silvia Bahadian Moreira ${ }^{3}$, Luiz Cesar C.P. da Silva ${ }^{3}$, Isabel M.A. Freire ${ }^{3}$, \\ Patrícia Oliveira Maciel ${ }^{3}$ e Nádia Regina P. Almosny ${ }^{5}$
}

\begin{abstract}
Silva W.B., Machado C., Goldberg D.W., Moreira S.B., Silva L.C.C.P., Freire I.M.A., Maciel P.O. \& Almosny N.R. 2009. [Assessment of blood inflammatory response in BCG stimulated rattlesnakes (Crotalus durissus Linnaeus, 1758).] Avaliação da resposta hematológica em cascavéis (Crotalus durissus Linnaeus, 1758) inoculadas com BCG. Pesquisa Veterinária Brasileira 29(12):985-992. Programa de PósGraduação em Clínica e Reprodução Animal, Faculdade de Medicina Veterinária, Universidade Federal Fluminense, Rua Vital Brazil Filho 64, Niterói, RJ 24230-360, Brazil. E-mail: wellban@yahoo.com.br

The high demand for anti-venom production in response to the increased number of cases of snakebite envenomation highlights the importance of raising and breeding venomous snakes in captivity. Knowledge of types of venoms and anti-venoms is of great interest to public health. The maintenance of venomous serpents in captivity started in the early twentieth century, but still nowadays it is a challenge to manage and prevent diseases in captive fauna. Hematology is commonly used for general health assessment and illness detection. However, data on serpent blood analysis are still scarce. Alterations in hematological parameters were experimentally induced in rattlesnakes by the inoculation of BCG. Based on this, hemograms can be used as a health auxiliary diagnosis method for bacterial diseases in this species. In this study, blood samples were taken from 10 healthy specimens of rattlesnakes (Crotalus durissus) born and bred in captivity in the Herpetological Division of Vital Brazil Institute. Animals were divided into two groups (group 1 and 2) with similar live weight and sex proportion, and were then inoculated subcutaneously with BCG (Bacillus Calmette-Guérin). Blood samples were taken before and after inoculation at three experimental times (days 3, 5 and 7 for group 1 and days 11,17 and 21 for group 2). Hematological analysis was performed through semi-direct technique, blood samples were diluted in Natt and Herrick solution and smears were stained by Giemsa. Serpents from group 1 developed discrete anemia due to the inflammatory syndrome, and showed significant decrease of $\mathrm{MCH}$ and $\mathrm{MCHC}$. Granulocytes were characterized by the presence of rough granules. The azurophils varied in shape and size and showed large amount of cytoplasmic vacuoles. The thrombocytopenia observed in group 2 suggests that these cells participate in the inflammatory process. A single individual from group 1 showed granulocytosis and a few animals showed a discrete azurophilia. In general, BCG inoculation unleashes
\end{abstract}

\footnotetext{
${ }^{1}$ Recebido em 17 de agosto de 2009.

Aceito para publicação em 11 de novembro de 2009.

${ }^{2}$ Mestrando do Programa de Pós-Graduação em Medicina Veterinária (Clínica e Reprodução Animal), Centro de Ciências Médicas, Faculdade de Medicina Veterinária (FMV), Universidade Federal Fluminense (UFF), Rua Vital Brazil Filho 64, Vital Brazil, Niterói, RJ 24230-360, Brasil. *Autor para correspondência: wellban@yahoo.com.br
}

\footnotetext{
${ }^{3}$ Departamento de Patologia Clínica Veterinária, Centro de Ciências Médicas, FMV-UFF, Niterói, RJ.

${ }^{4}$ Divisão de Herpetologia, Instituto Vital Brazil, Rua Maestro José Botelho 64, Vital Brazil, Caixa. Postal 100.028, Niteroi, RJ 24230410.

${ }^{5}$ Docente do Programa de Pós-Graduação em Medicina Veterinária (Clínica e Reprodução Animal), FMV-UFF, Niterói, RJ.
} 
hematological inflammatory responses characterized by the presence of thrombocytes, azurophils and granulocytes cells.

INDEX TERMS: Crotalus durissus, inflammation, BCG, hematology, reptile.

RESUMO.- A criação de serpentes peçonhentas em cativeiro para produção de soros antipeçonhas possui crescente importância para a saúde pública devido ao aumento do número de notificações de acidentes ofídicos a cada ano no Brasil. Iniciado no século XX, ainda hoje essa atividade apresenta alguns desafios como a instalação de doenças no plantel. O hemograma é um exame de triagem clínica que auxilia no diagnóstico de diversas moléstias que acometem diferentes espécies de animais, no entanto ainda pouco estudado em serpentes. A caracterização das alterações hematológicas em cascavéis inoculadas experimentalmente com BCG pode servir de base na utilização deste exame no auxílio ao diagnóstico de infecções bacterianas na espécie. Dessa forma, foram realizados exames hematológicos em 10 serpentes da espécie Crotalus durissus pertencentes ao plantel da Divisão de Herpetologia do Instituto Vital Brazil. Os animais foram divididos em dois grupos (Grupos 1 e 2), homogêneos entre si em relação ao peso e proporção sexual. Os dois grupos foram inoculados com BCG e submetidos à coleta de sangue antes da inoculação e em três momen-

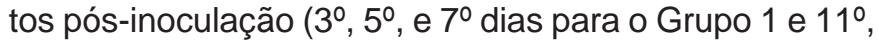
$17^{\circ}$ e $21^{\circ}$ dias para o Grupo 2). O hemograma foi realizado por método semidireto pela utilização de líquido de Natt e Herrick e as lâminas foram coradas pelo Giemsa. Observou-se anemia discreta, com redução dos valores de concentração de hemoglobina corpuscular média e da hemoglobina globular média no Grupo 1 que foi relacionada à doença inflamatória. A trombocitopenia observada no Grupo 2 sugeriu a atuação deste tipo celular em processos inflamatórios. Um único animal do Grupo 1 apresentou granulocitose e alguns animais apresentaram discreta azurofilia. Observaram-se alterações morfológicas nos leucócitos. Os granulócitos apresentaram granulações grosseiras e os azurófilos apresentaram aumento de tamanho e grandes vacúolos. De forma geral, a inoculação de BCG em cascavéis desencadeia respostas inflamatórias hematológicas caracterizadas pela participação de trombócitos, granulócitos e azurófilos.

TERMOS DE INDEXAÇÃO: Crotalus durissus, Inflamação, BCG, hematologia, répteis.

\section{INTRODUÇÃO}

O número de notificações de acidentes ofídicos vem aumentando a cada ano no Brasil com a espécie Crotalus durissus, responsável por cerca $9,2 \%$ do total de notificações, variando de acordo com a região (Araújo et al. 2003). Somado a isso, essa espécie tem aumentado sua distribuição e densidade no Rio de Janeiro devido ao aumento da fragmentação florestal, resultado do crescimento desordenado das cidades (Bastos et al. 2005). Os dados epidemiológicos mostram o aumento da demanda de soro antipeçonhento em todo Brasil evidenciando a importância para a saúde pública da criação de serpentes peçonhentas em cativeiro. Por esta razão o conhecimento do manejo e da clínica destes animais se torna importante a fim de permitir maior sobrevida do animal.

Considerado como exame de triagem clínica, o hemograma é utilizado no auxílio ao diagnóstico, no acompanhamento clínico e no prognóstico de diversas moléstias que acometem os animais (Almosny \& Monteiro 2007). Embora existam trabalhos de décadas passadas, relativamente pouco se sabe sobre hematologia e sobre o desenvolvimento da resposta inflamatória em répteis. A classificação celular nestas espécies se mostra divergente, talvez devido a comparações com espécies distantes evolutivamente como mamíferos e aves.

Uma ferramenta utilizada na classificação funcional dos tipos celulares observados no sangue de cascavéis é a avaliação do comportamento celular sob diferentes estímulos patológicos experimentalmente induzidos ou naturalmente observados. A inoculação de cepas atenuadas de Mycobacterium tem sido utilizada no estudo da resposta hematológica em animais endotérmicos e ectotérmicos (Marcus et al.1975, Buddle \& Young 2000, Sado \& Matushima 2008). O bacilo de Calmette-Guérin (BCG) é um derivado do Mycobacterium bovis atenuado, e vem sendo utilizado hoje em dia para a imunização vacinal contra a tuberculose, como veículo recombinante para vacinas multivalentes para outras doenças infecciosas e para a imunoterapia do câncer (Nunes 2004).

Sendo assim, o objetivo desse estudo foi avaliar a dinâmica leucocitária e eritrocitária, decorrente do processo inflamatório induzido pela inoculação de BCG em cascavéis, através de exames hematológicos seriados realizados nos animais antes e depois de inoculados.

\section{MATERIAL E MÉTODOS}

Foram utilizadas 10 serpentes da espécie Crotalus durissus, machos e fêmeas, nascidos e criados na Divisão de Herpetologia do Instituto Vital Brazil (IVB, Niterói, RJ) com idade de três a quatro anos, com a finalidade principal de extração de veneno para produção de soro antipeçonha. Os animais foram selecionados após constatação de sanidade por exame físico e observação de agressividade normal para a espécie. Os animais selecionados foram divididos em dois grupos (Grupo 1 e 2) de forma a manter a homogeneidade em relação ao peso e proporção sexual entre eles. Todos os animais foram excluídos da rotina de extração de veneno no período do experimento.

Os animais foram acondicionados individualmente em caixas retangulares de polipropileno leitoso $(50 \times 35 \times 16 \mathrm{~cm}$, comprimento $x$ largura $x$ altura), devidamente identificadas e mantidas dentro de uma sala à temperatura ambiente $\left(25-30^{\circ} \mathrm{C}\right)$. Antes e durante o experimento, os animais foram regularmente alimentados uma vez ao mês com dois camundongos de biotério e com livre acesso a água, conforme rotina do serpentário. Quarenta dias 
antes de se iniciar o experimento, preconizou-se o uso de Ivermectina $\left(\right.$ Ivomec $\left.^{\circledR}\right)$, Levamizole (Ripercol $\left.{ }^{\circledR}\right)$ e Fipronil 10\% (Frontline ${ }^{\circledR}$ Spray) segundo Carpenter et al. (2004) para controle de endoparasitas e ectoparasitas.

Coletas de sangue para realização dos exames controle, caracterizando os valores de normalidade para os espécimes estudados, foram realizadas nos dois grupos, 14 dias antes da inoculação. Para indução do estímulo inflamatório, foram utilizados 0,05ml de Imuno-BCG (Bacilo Calmette-Guerin, Fundação Ataulpho de Paiva), na concentração de $80 \mathrm{mg} / \mathrm{ml}$. A inoculação foi realizada por via intramuscular na região dorsal, do lado direito, aproximadamente entre a junção do terço cranial e medial do animal. $O$ Grupo 1 foi submetido à coleta de sangue no $3^{\circ}, 5^{\circ}$, e $7^{\circ}$ dias após serem inoculados com BCG e o Grupo 2 no $11^{\circ}, 17^{\circ}$ e $21^{\circ}$ dias pós-inoculação.

As amostras sanguíneas foram coletadas através de punção da veia coccígea ventral (Campbell 2004, Almosny \& Monteiro 2007). Foi coletado cerca $0,5 \mathrm{ml}$ de sangue de cada animal utilizando agulha $20 \times 5,5$ e seringa de $1 \mathrm{ml}$, que foram armazenados em frasco plástico de fundo cônico (Eppendorf ${ }^{\circledR}$ ) previamente rinsados com heparina sódica $5.000 \mathrm{Ul} / \mathrm{ml}$ (Liquemine ${ }^{\circledR}$ ). Esfregaços sanguíneos sem anticoagulante foram confeccionados no momento da coleta.

Para contagem global dos tipos celulares preconizou-se a diluição do sangue em líquido de Natt e Herrick (Natt \& Herrick 1952) na proporção de 1:100 e contagens na câmara de Neubauer ${ }^{\circledR}$ Improved, com auxílio de microscópio óptico, em aumento de 400 vezes. As hemácias foram contadas concomitantemente com a contagem conjunta dos leucócitos e trombócitos. Os valores obtidos foram multiplicados pelo fator de correção, sendo os resultados expressos em número de células/ $\mathrm{mm}^{3}$. O volume globular foi determinado pela técnica do microhematócrito que consiste na centrifugação de tubos capilares preenchidos com sangue a 10.000 rpm por 5 minutos segundo Campbell (2004). As dosagens de hemoglobina foram realizadas pelo método da cianometahemoglobina, segundo Campbell (2004). Uma solução com $5 \mathrm{ml}$ de reagente de cor (Labtest Diagnóstica ${ }^{\circledR}$ ) e $20 \mu l$ de sangue total foi preparada para reação colorimétrica, sendo centrifugada a 3.000 rpm por 5 minutos, a fim de precipitar o núcleo das hemácias (Raskin 2000, Campbell 2004, 2006). A absorbância da amostra foi medida em analisador bioquímico semi-automático Bioplus $2000^{\circledR} \mathrm{em}$ $540 \mathrm{~nm}$. O fator de calibração utilizado $(36,20)$ foi obtido com o padrão de hemoglobina. Os esfregaços sanguíneos foram fixados por dois minutos em metanol e imersos por trinta minutos em solução de Giemsa (Merck ${ }^{\circledR}$ ) a $5 \%$ em água destilada.

A leucometria específica foi realizada em microscopia óptica, aumento de 1000 vezes, seguindo-se um padrão de leitura em guarda grega em suas duas bordas. Foram contados 100 leucócitos, os quais foram diferenciados em basófilos, granulócitos, azurófilos, linfócitos e monócitos adaptando-se a nomenclatura descrita por Montali (1988), Troiano et al. (1997) e Almosny \& Monteiro (2007). Uma contagem paralela de trombócitos foi realizada durante a contagem dos leucócitos a fim de determinar a proporção entre estes dois tipos celulares.

Para permitir uma visão geral dos perfis estudados na população, foi calculado a média e o desvio-padrão de cada variável analisada na pesquisa. Para verificação de diferenças significativas entre os grupos $(p<0,01)$, foi realizada análise de variância (ANOVA) para as variáveis entre os grupos antes da inoculação.

As distribuições das variáveis foram submetidas aos testes estatísticos de Qui-quadrado, Kolmogorov-Smirnov e AndersonDarling, no intuito de se verificar sua compatibilidade com a curva de normalidade e a pertinência de aplicação de testes paramétricos ou não-paramétricos. $O$ critério de decisão foi o de considerar incompatível com testes paramétricos qualquer distribuição que apresentasse significância $(p<0,05)$ em pelo menos dois dos três testes aplicados. Nas variáveis com distribuições normais, foi empregado ANOVA para a verificação de diferenças significativas $(p<0,05)$ entre as respectivas variâncias das coletas dentro dos grupos. Quando o resultado do ANOVA indicou significância, foram realizados quatro testes estatísticos (Teste de Duncan, Fisher, Scheffe e Tukey-Kramer), a fim de se localizar a coleta em que ocorreu a alteração. Quando as distribuições não se mostraram compatíveis com a curva de distribuição normal, as respectivas comparações foram efetuadas por intermédio de testes de Kruskal-Wallis.

\section{RESULTADOS E DISCUSSÃO}

A análise estatística mostrou não haver diferenças em nenhuma das variáveis $(p>0,01)$, entre os animais dos dois grupos antes do experimento, convencionando-se assim, que os dois grupos eram uniformes entre si.

As hemácias apresentaram-se, em sua maior parte, como o descrito pela literatura (Frye 1991, Campbell 1996, Rodrigues 2000, Grego et al. 2006). Eritrócitos jovens foram observados com maior freqüência nos animais com volume globular mais baixo, no entanto, esta característica pode não estar relacionada ao processo inflamatório. De fato, uma moderada poiquilocitose e um intenso pleomorfismo nuclear foram observados em animais sadios. Eritrócitos jovens em animais sadios podem estar presentes tanto fisiologicamente como em animais que reali-

Quadro 1. Eritrograma das cascavéis do grupo 1. Valores observados antes (coleta 1) e depois (coletas 2, 3 e 4) de inoculados com BCG. (Média \pm DP)

\begin{tabular}{ccccc}
\hline & $\begin{array}{c}\text { Coleta 1 } \\
\text { Pré-inoculação }\end{array}$ & $\begin{array}{c}\text { Coleta 2 } \\
\text { dias após a } \\
\text { inoculação }\end{array}$ & $\begin{array}{c}\text { Coleta 3 } \\
\text { dias após a } \\
\text { inoculação }\end{array}$ & $\begin{array}{c}\text { Coleta 4 } \\
7 \text { dias após a } \\
\text { inoculação }\end{array}$ \\
\hline VG (\%) & $20,8 \pm 3,8$ & $21,0 \pm 3,7$ & $20,0 \pm 2,5$ & $20,0 \pm 2,3$ \\
Hematimetria $\left(10^{6} / \mathrm{mm}^{3}\right)$ & $0,377 \pm 0,104$ & $0,390 \pm 0,080$ & $0,395 \pm 0,066$ & $0,420 \pm 0,048$ \\
Hemoglobina $(\mathrm{g} / \mathrm{dl})$ & $5,5 \pm 1,1$ & $5,8 \pm 1,2$ & $4,2 \pm 0,7$ & $5,6 \pm 1,1$ \\
VGM (fl) & $569,6 \pm 92,1$ & $540,42 \pm 25,2$ & $510,1 \pm 46,2$ & $479,4 \pm 59,7$ \\
CHGM (\%) & $26,2 \pm 0,8$ & $27,6 \pm 1,3$ & $21,3 \pm 3,0$ & $27,7 \pm 2,5$ \\
HGM (pg) & $148,9 \pm 21,6$ & $149,2 \pm 5,8$ & $108,1 \pm 13,0$ & $133,2 \pm 22,7$ \\
\hline
\end{tabular}

VG = Volume globular; VGM = Volume Globular Médio; $C H G M=$ Concentração de Hemoglobina Globular Média; HGM = Hemoglobina Globular Média; DP = Desvio padrão. 


\begin{tabular}{|c|c|c|c|c|}
\hline & $\begin{array}{c}\text { Coleta } 1 \\
\text { Pré-inoculação }\end{array}$ & $\begin{array}{c}\text { Coleta } 2 \\
11 \text { dias após a } \\
\text { inoculação }\end{array}$ & $\begin{array}{c}\text { Coleta } 3 \\
17 \text { dias após a } \\
\text { inoculação }\end{array}$ & $\begin{array}{c}\text { Coleta } 4 \\
21 \text { dias após a } \\
\text { inoculação }\end{array}$ \\
\hline VG $(\%)$ & $19,6 \pm 1,8$ & $22,2 \pm 2,6$ & $21,6 \pm 2,7$ & $20,0 \pm 3,7$ \\
\hline Hematimetria $\left(10^{6} / \mathrm{mm}^{3}\right)$ & $0,394 \pm 0,048$ & $0,439 \pm 0,092$ & $0,425 \pm 0,082$ & $0,369 \pm 0,071$ \\
\hline Hemoglobina (g/dl) & $5,0 \pm 0,7$ & $6,2 \pm 0,9$ & $5,8 \pm 0,7$ & $5,5 \pm 1,0$ \\
\hline VGM (fl) & $500,5 \pm 40,4$ & $514,5 \pm 55,2$ & $517,0 \pm 74,2$ & $547,3 \pm 77,6$ \\
\hline CHGM (\%) & $25,3 \pm 2,4$ & $28,1 \pm 1,1$ & $26,7 \pm 1,5$ & $27,54 \pm 0,7$ \\
\hline HGM (pg) & $125,9 \pm 9,8$ & $144,0 \pm 11,6$ & $137,8 \pm 20,8$ & $150,6 \pm 20,1$ \\
\hline
\end{tabular}

VG = Volume globular; VGM = Volume Globular Médio; $C H G M=$ Concentração de Hemoglobina Globular Média; HGM = Hemoglobina Globular Média; DP = Desvio padrão.

zam ecdise (Frye 1991, Canfield 1998, Alleman et al. 1999, Campbell 1996, 2004, Almosny \& Monteiro 2007) como ocorreu no período do experimento. Os valores encontrados no eritrograma estão dispostos no Quadro 1 (Grupo 1) e Quadro 2 (Grupo 2).

Não foram observadas diferenças significativas para hematimetria, volume globular e VGM, nos animais nos dois grupos.

Os valores de hemoglobinometria não apresentaram diferenças significativas entre os grupos. Contudo, os valores de hemoglobina na coleta 3 do Grupo 1 foram menores do que as demais coletas. Esta redução na hemoglobinometria foi observada pelos valores de $\mathrm{CHGM} \mathrm{e}$ HGM, que apresentaram diferença significativa $(p<0,05)$. Em inflamações agudas e crônicas observa-se a instalação de uma anemia hipocrômica (ou normocrômica), com diminuição da hemoglobina e do ferro plasmático. O mecanismo de instalação desta anemia é mediado por citocinas inflamatórias e parece estar ligado a um bloqueio da liberação do ferro reciclado por parte dos macrófagos. Durante processos infecciosos, esse mecanismo tem a função de indisponibilizar o ferro para os microrganismos, os quais em geral necessitam deste mineral para o seu crescimento (Alencar et al. 2002, Lorenzi et al. 2003, Campbell 2004). Se avaliarmos a dinâmica da instauração do quadro de microcitose, oligocitemia e hipocromia presentes nesse tipo de anemia em mamíferos e répteis (Lorenzi et al. 2003, Campbell 2004), pode-se supor que a diminuição do HGM e CHGM observada reflita o início da instalação de uma anemia por doença inflamatória, visto que a queda do volume globular e da hematimetria neste tipo de anemia é, em geral, discreta, e possivelmente ainda imperceptível no grupo.

Os trombócitos íntegros observados no sangue das cascavéis apresentaram-se morfologicamente semelhantes com o descrito pela literatura (Mader 2000, Rodrigues 2000, Rosskopf 2000, Campbell 2004, 2006, Almosny \& Monteiro 2007). Embora tenham sido observados trombócitos binucleados, não foi possível estabelecer uma correlação destes com quadros anêmicos, tampouco a uma possível capacidade de esta célula realizar divisão e se diferenciar em eritrócitos, tal como descreve Frye (1991). Segundo Campbell (1996), trombócitos com polimorfismo nuclear estão freqüentemente associados a doenças inflamatórias, no entanto, não foi observado aumento dessa característica em nenhum animal.

Os valores encontrados na contagem de trombócitos estão dispostos no Quadro 3 (Grupo 1) e Quadro 4 (Grupo 2). Foi observada uma diminuição significativa na contagem absoluta de trombócitos na coleta 4 do Grupo 2 (21 dias após a inoculação). Em geral, condições patológicas com presença de endotoxinas podem causar lesões vasculares, que culminam em quebra da homeostasia sanguínea, por interromper o equilíbrio na produção de substâncias procoagulantes e anticoagulantes, além de expor o subendotélio, ativando fatores tissulares da coagulação. Com isso inicia-se a formação de coágulos com ativação trombocitária e do sistema fibrinolítico, aumen-

\begin{tabular}{|c|c|c|c|c|}
\hline & $\begin{array}{c}\text { Coleta } 1 \\
\text { Pré-inoculação }\end{array}$ & $\begin{array}{c}\text { Coleta } 2 \\
3 \text { dias após a } \\
\text { inoculação }\end{array}$ & $\begin{array}{c}\text { Coleta } 3 \\
5 \text { dias após a } \\
\text { inoculação }\end{array}$ & $\begin{array}{c}\text { Coleta } 4 \\
7 \text { dias após a } \\
\text { inoculação }\end{array}$ \\
\hline LG & $12903,2 \pm 6.856,0$ & $14430,9 \pm 6366,8$ & $13127,1 \pm 11607,1$ & $14887,9 \pm 8582,2$ \\
\hline Basófilo & $0,0 \pm 0,0$ & $0,0 \pm 0,0$ & $0,0 \pm 0,0$ & $0,0 \pm 0,0$ \\
\hline Granulócito & $4661,2 \pm 3937,6$ & $4952,3 \pm 5264,0$ & $5973,4 \pm 9114,9$ & $5398,2 \pm 7502,4$ \\
\hline Linfócito & $5026,0 \pm 2477,5$ & $7209,7 \pm 3642,4$ & $3510,6 \pm 2424,6$ & $5752,2 \pm 2858,8$ \\
\hline Monócito & $61,5 \pm 103,4$ & $92,5 \pm 98,8$ & $88,5 \pm 90,0$ & $36,7 \pm 50,3$ \\
\hline Azurófilo & $3134,4 \pm 2339,4$ & $2176,4 \pm 977,9$ & $3554,7 \pm 3353,3$ & $3700,8 \pm 3118,8$ \\
\hline Trombocito & $11596,8 \pm 5702,9$ & $7769,1 \pm 2355,8$ & $6372,9 \pm 2854,4$ & $10952,1 \pm 3813,0$ \\
\hline
\end{tabular}




\begin{tabular}{|c|c|c|c|c|}
\hline & $\begin{array}{c}\text { Coleta } 1 \\
\text { Pré-inoculação }\end{array}$ & $\begin{array}{l}\text { Coleta } 2 \\
11 \text { dias após a } \\
\text { inoculação }\end{array}$ & $\begin{array}{c}\text { Coleta } 3 \\
17 \text { dias após a } \\
\text { inoculação }\end{array}$ & $\begin{array}{c}\text { Coleta } 4 \\
21 \text { dias após a } \\
\text { inoculação }\end{array}$ \\
\hline LG & $11161,2 \pm 7017,8$ & $11521,2 \pm 4300,2$ & $9872,2 \pm 5835,5$ & $8819,9 \pm 2472,3$ \\
\hline Basófilo & $46,0 \pm 102,8$ & $58,2 \pm 84,3$ & $31,2 \pm 48,3$ & $0,0 \pm 0,0$ \\
\hline Granulócito & $2602,7 \pm 2897,7$ & $2651,1 \pm 3799,8$ & $2554,5 \pm 4222,2$ & $365,8 \pm 564,3$ \\
\hline Linfócito & $6090,4 \pm 4633,9$ & $6610,8 \pm 1826,9$ & $5493,5 \pm 2607,7$ & $6442,3 \pm 2350,0$ \\
\hline Monócito & $313,5 \pm 240,3$ & $143,4 \pm 105,3$ & $338,9 \pm 324,5$ & $0,0 \pm 0,0$ \\
\hline Azurófilo & $2018,2 \pm 1673,7$ & $2057,7 \pm 1179,0$ & $1463,3 \pm 629$ & $1985,5 \pm 1196,0$ \\
\hline Trombócitos & $12738,8 \pm 3167,4$ & $13478,8 \pm 4111,4$ & $10527,8 \pm 628,7$ & $8180,1 \pm 920,4$ \\
\hline
\end{tabular}

LG = Leucometria global; DP = Desvio padrão.

tando-se a demanda trombocitária (Russel \& Grindem 2000). Visto que o grupo1 não apresentou uma trombocitopenia devido ao aumento da demanda de trombócitos pelas lesões vasculares causado pelas repetidas coletas, sugere-se que a trombocitopenia observada no Grupo 2 possa ser decorrente do processo inflamatório em questão.

Os valores encontrados na leucometria estão dispostos no Quadro 3 (Grupo 1) e Quadro 4 (Grupo 2). Não foram observadas diferenças significativas na leucometria global e na específica entre as coletas nos dois grupos.

Assim como ocorre em outras espécies de vertebrados, a freqüência de basófilos observada neste experimento foi bastante baixa e não foram observadas alterações morfológicas neste tipo leucocitário (Frye 1991, Dotson et al. 1995, Campbell 1996, Raskin 2000, Rodrigues 2000, Almosny \& Monteiro, 2007).

O número de granulócitos não apresentou alterações significativas entre as coletas nos dois grupos estudados

\section{Granulócitos nㅇ/m $\mathrm{m}^{3}$}

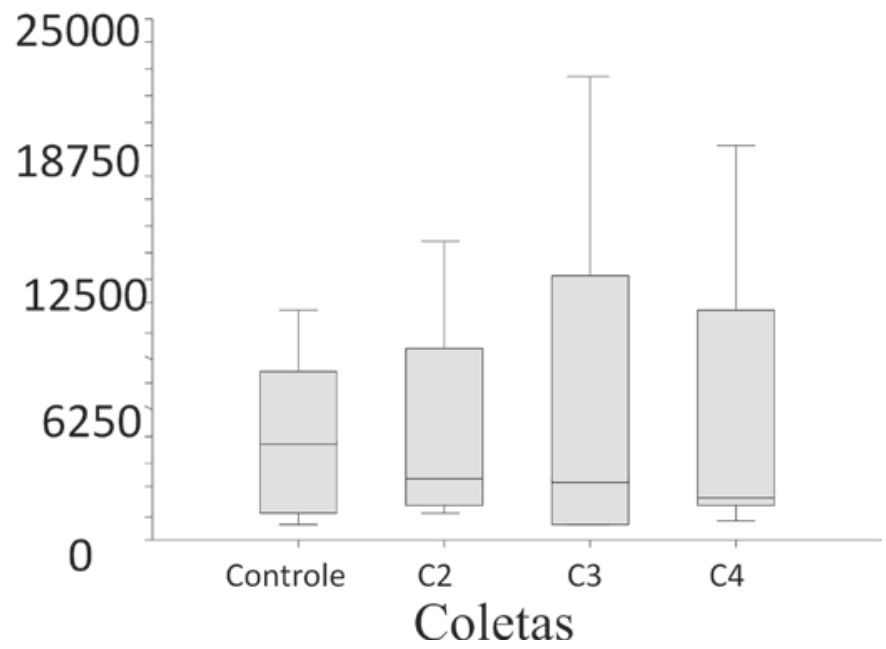

Fig.1. Valores gráficos do número de granulócitos observados no sangue de cascavéis nas quatro coletas realizadas no Grupo 1. O aumento somente dos valores máximos indicam um incremento da contagem deste tipo celular em um único animal. C2 = coleta $2, \mathrm{C} 3=$ coleta $3, \mathrm{C} 4=$ coleta 4.

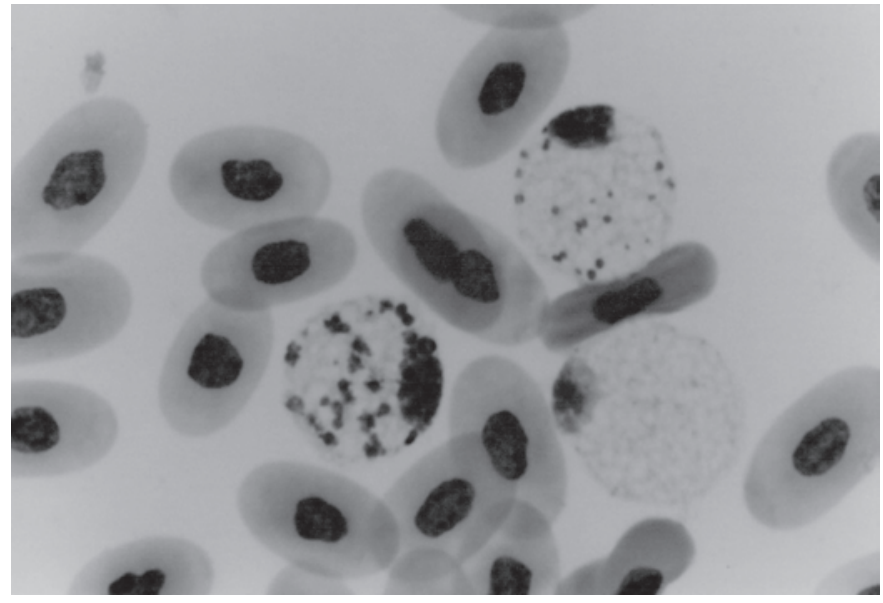

Fig.2. Três granulócitos de Crotalus durissus apresentando quantidades variáveis de grânulos basofílicos no citoplasma. Giemsa, obj.100x.

$(p>0,05)$. No entanto, observou-se que um animal apresentou um aumento deste tipo celular a partir da coleta 2 (Fig.1). Morfologicamente, dois animais do grupo 1 apresentaram granulócitos com quantidades crescentes de grânulos basofílicos no citoplasma a partir da coleta 2 (Fig.2). Estes grânulos caracterizaram-se por possuírem formato redondo, porém de contorno irregular e pouco definido. Coraram-se de roxo, mais intenso no centro do que na periferia, e apresentaram-se de vários tamanhos. Embora esta característica tenha sido mais intensa nestes animais, outros animais dos dois grupos apresentaram granulócitos com poucos grânulos antes da inoculação com BCG sugerindo que haja uma liberação de formas tóxicas deste tipo celular, mesmo quando ainda não houve um aumento deste na circulação. Alguns autores sugerem a possibilidade do granulócito de répteis possuir funções biológicas semelhantes aos neutrófilos de mamíferos e aos heterófilos de aves (Campbell 1994, Fudge 2000). Em mamíferos, os neutrófilos são os tipos leucocitários que formam a primeira linha de defesa do organismo contra germes patogênicos (Lorenzi et al. 2003); o mesmo se observa nas aves para os heterófilos (Campbell 1994, Fudge 2000, Latimer \& Bienzle 2000). De fato, a presença de granulócitos é marcante no foco inflamatório 
no tecido, tal como descrito em diversos trabalhos (Mateo et al.1984a,b, Smith \& Barker 1988, Smith et al. 1988a,b, Frye 1991, Jacobson et al. 1991, Tucunduva et al. 2001). Alterações morfológicas nos neutrófilos e heterófilos são muitas vezes indicativas do processo patológico que as causou. A presença de neutrófilos tóxicos em mamíferos está diretamente relacionada ao aumento da demanda deste tipo celular devido a processos inflamatórios severos, e as alterações citadas podem ser causadas por faIhas na maturação da célula (Almosny \& Monteiro, 2007). Em mamíferos, os neutrófilos tóxicos caracterizam-se pela presença de basofilia citoplasmática, presença de vacuolizações e de granulações tóxicas, resultado da retenção de mucopolissacarídeos no citoplasma celular (Smith 2000). Da mesma forma, granulócitos tóxicos em répteis também são descritos em infecções bacterianas agudas, caracterizando-se pela intensa basofilia citoplasmática, com freqüente vacuolização e granulação basofílica grosseira (Smith 2000, Stockham 2000, Campbell 2006). Dessa forma, a presença de granulações tóxicas observadas em granulócitos aparentemente possui ligação com o aumento da demanda deste tipo celular, como resposta à inflamação.

Os mesmos animais que apresentaram alterações morfológicas nos granulócitos apresentaram azurófilos com grande quantidade de vacúolos citoplasmáticos de tamanhos variados e com inclusões negras de tamanhos e formatos variados em seu citoplasma, nas coletas 3 e 4 do Grupo 1 (Fig.3). Alguns animais apresentaram azurófilos aumentados de tamanho nas coletas pós-inoculação, chegando a serem maiores do que o tamanho de duas hemácias. Observou-se nestes também, um número maior de grandes vacúolos (Fig.4). Não foram observadas alterações significativas no número de azurófilos $(p>0,05)$. Embora as alterações morfológicas dos azurófilos tenham sido mais intensas num número reduzido de animais, os demais apresentaram as mesmas alterações de forma mais discretas. Os autores que consideram o azurófilo um tipo monocitário descrevem as causas de azurofilia

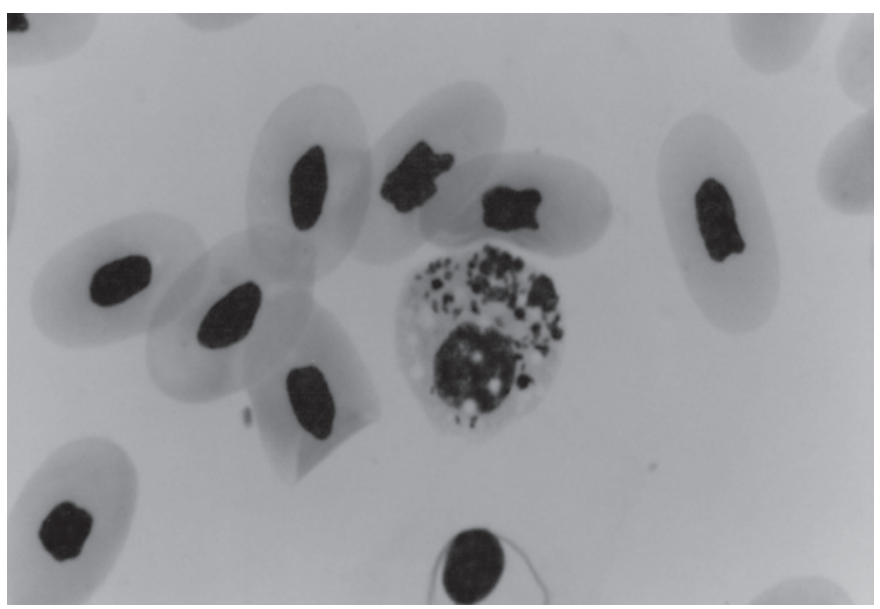

Fig.3. Azurófilo de Crotalus durissus com grande quantidade de Grânulos. Giemsa, obj.100x.

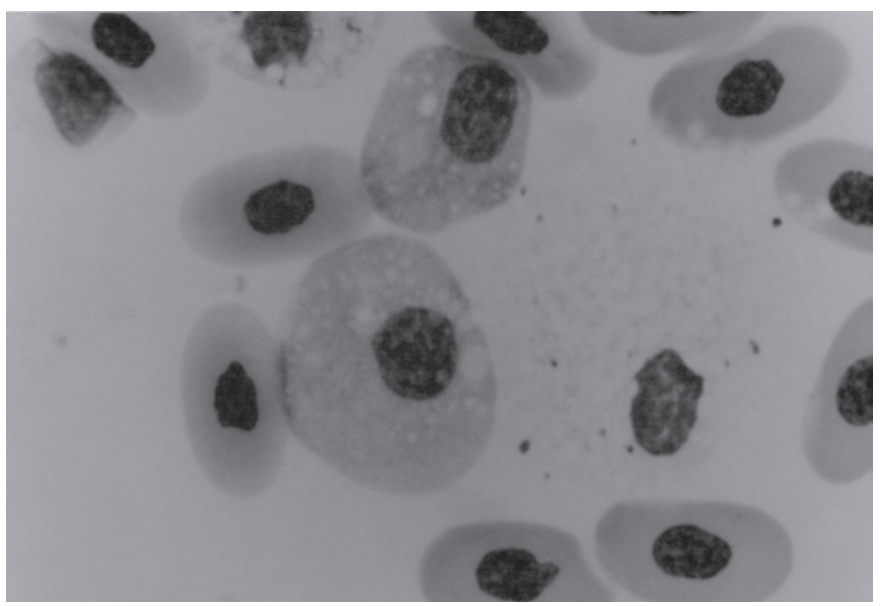

Fig.4. Azurófilo grande de Crotalus durissus. Nota-se a presença de grandes vacúolos citoplasmáticos. Giemsa, obj.100x.

como sendo as mesmas que acarretariam uma monocitose em aves e mamíferos. Segundo Rosskopf (2000), doenças granulomatosas crônicas são as principais causas de azurofilia em répteis. É esperado que, ao se inocular uma espécie atenuada de Mycobacterium, ocorra tecidualmente um processo inflamatório granulomatoso nestes animais, tal como observado por Sado \& Matushima (2008) em peixes. A presença de azurófilos grandes, pleomórficos e intensamente vacuolados sugere, por analogia morfológica, sua origem monocítica. De fato, os monócitos de mamíferos e aves são células caracteristicamente pleomórficas e em seu estado maturativo tecidual, o macrófago, é tido como uma célula ainda mais variável, de tamanho maior, com núcleos grandes e apresentando grandes vesículas citoplasmáticas (Bienzle 2000, Latimer \& Bienzle 2000). Quanto às granulações observadas, estas seguem o mesmo critério de classificação dos granulócitos tóxicos, e, como afirma Frye (1991), as granulações tóxicas podem estar presentes em quadros de septicemia. Contudo, a indefinição acerca da natureza deste tipo celular dificulta a interpretação dos dados obtidos.

Os monócitos apresentaram-se em conformidade com o descrito pela literatura (Saint Girons 1970, Frye 1991, Campbell 1996, 2004, 2006, Canfield 1998, Mader 2000, Raskin 2000, Rodrigues 2000) e não foram observadas alterações morfológicas neste tipo celular. Quantitativamente foram leucócitos pouco freqüentes e não apresentaram diferenças significativas entre as coletas dos dois grupos $(p>0,05)$.

Os valores dos linfócitos não apresentaram diferenças significativas entre as coletas. Morfologicamente, foi observada a presença de linfócitos ativados e plasmócitos. Estas células se apresentaram com núcleo pequeno, apresentando cromatina densa e coloração fortemente enegrecida (Jacobson 1984, Frye 1991, Campbell 1996, 2004, 2006, Raskin 2000). O citoplasma, mais abundante, apresentou-se intensamente basofílico a enegrecido nos plasmócitos evidenciando uma leve granulação. A 
presença de uma área esbranquiçada perinuclear, relativa ao Complexo de Golgi, foi uma característica marcante deste tipo celular.

\section{CONCLUSÕES}

Frente às condições experimentais descritas neste trabaIho conclui-se que:

- Apesar de serem necessários mais estudos nesta área de conhecimento, as alterações morfológicas observadas nos granulócitos e nos azurófilos sugerem a participação destes tipos celulares no processo inflamatório experimentalmente induzido pela inoculação do BCG, evidenciando a importância da hematoscopia como investigação diagnóstica nesses animais.

- A discreta diminuição do CHGM e HGM observada sugere a instalação de uma anemia pela inflamação cujos mecanismos ainda carecem de maiores estudos.

- Da mesma forma sugere-se a participação dos trombócitos no processo inflamatório pela trombocitopenia observada.

- As análises quantitativas dos eritrócitos e dos leucócitos não refletiram alterações significativas frente ao estímulo inflamatório experimentalmente induzido e carecem de mais estudos frente a outros protocolos experimentais.

Agradecimentos.- À Coordenação de Aperfeiçoamento de Pessoal de Nível Superior (CAPES) pelo suporte financeiro cedido a este projeto. Aos profissionais do Instituto Vital Brazil por permitir a execução deste trabalho e pela ajuda na contenção e manutenção dos animais. Ao professor Sérgio Bastos Moreira pela grande ajuda na organização e na análise estatística dos dados.

\section{REFERÊNCIAS}

Alencar N.X., Kohayagawa A. \& Campos K.C.H. 2002. Metabolismo do ferro nos animais domésticos: revisão. Revta. Educ. Cont. CRMV-SP 5(2):196-205.

Almosny N.R.P. \& Monteiro A.M. 2007. Patologia clínica, p.939-966. In: Cubas Z.S., Silva J.C.S. \& Catão-Dias J.L. (Eds), Tratado de Animais Selvagens: medicina veterinária. Roca, São Paulo.

Alleman A.R., Jacobson E.R. \& Raskin R.E. 1999. Morphologic, cytochemical staining, and ultrastructural characteristics of blood cells from eastern diamondback rattlesnakes (Crotalus adamanteus). Am. J. Vet. Res. 60(4):507-514.

Araújo F.A.A, Santalúcia M. \& Cabral R.F. 2003. Epidemiologia dos acidentes por animais peçonhentos, p.6-12. In: Cardoso J.L.C., França F.O.S., Wen F.H., Málaque C.M.S. \& Haddad Jr V. (Eds), Animais Peçonhentos no Brasil: biologia, clínica e terapêutica dos acidentes. Sarvier, São Paulo.

Bastos E.G.M., Araújo A.F.B. \& Silva H.R. 2005. Records of the rattlesnakes Crotalus durissus terrificus (Laurenti) (Serpentes, Viperidae) in the state of Rio de Janeiro, Brazil: A possible case of invasion facilitated by deforestation. Revta Bras. Zool. 22(3)812-815.

Bienzle D. 2000. Monocytes and macrophages, p.318-325. In: Feldman B.F., Zinkl J.G. \& Jain N.C. (Eds), Schalm's Veterinary Hematology. $5^{\text {th }}$ ed. Lippincott Williams and Wilkins, Philadelphia. 1344p.

Buddle B.M. \& Young L.J. 2000. Immunobiology of mycobacterial infections in marsupials. Rev. Comp. Immunol. 24(5):517-529.
Campbell T.W. 2006. Clinical pathology of reptiles, p.490-532. In: Mader D. R. (Ed.), Reptile Medicine and Surgery. Saunders Elsevier, St Louis, Missouri. 512p.

Campbell T.W. 1996. Clinical pathology, p.248-257. In: Mader D.R. (Ed.), Reptile Medicine and Surgery. W.B. Saunders, Philadelphia. 512p.

Campbell T.W. 1994. Hematology, p.176-198. In: Ritchie, Harrison \& Harrison (Eds), Avian Medicine: Principles and application. Wingers Publ., Florida. 1384p.

Campbell T.W. 2004. Hematology of reptiles, p.259-276 In: Thrall M.A, Baker D.C., Campbell T.W., DeNicola D.B., Fettman M.J., Lassen E.D., Rebar A. \& Weiser G. (Eds), Veterinary Hematology and Clinical Chemistry. Lippincott Williams and Wilkins, Baltimore. 505p.

Canfield P.J. 1998. Comparative cell morphology in the peripheral blood film from exotic and native animals. Aust. Vet. J. 76(12):793-800.

Carpenter J.W., Mashima T.Y. \& Rupiper, D.J. 2004. Antiparasitic agents used in reptiles, p.51-58. In: Carpenter J.W. (Ed.), Exotic Animal Formulary. $3^{\text {rd }}$ ed. W.B. Saunders, Philadelphia. 423p.

Dotson T.K., Ramsay E.R. \& Denise I.B. 1995. A color atlas of blood cells of the yellow rat snake. Small Anim. Compend. 17(8):10131026.

Frye F.L. 1991. Hematology as applied to clinical reptile medicine, p.209277. In: Frye L.F. (Ed.), Reptile Care: An atlas of diseases and treatments. T.F.H. Publications, New Jersey.

Fudge A.M. \& Joseph V. 2000. Disorders of avian leukocytes, p.19-27. In: Fudge A.M. (Ed.), Laboratory Medicine: Avian and exotic pets. W.B. Saunders, Philadelphia. 486p.

Grego K.F., Alves J.A.S., Rameh de Albuquerque L.C. \& Fernandes W. 2006. Referências hematológicas para a jararaca de rabo branco (Bothrops leucurus) recém-capturadas da natureza. Arq. Bras. Med. Vet. Zootec. 58(6):1240-1243.

Jacobson E.R. 1984. Biology and diseases of reptiles, p.449-476. In.: Fox J.G., Cohen B.J. \& Loew F.M. (Eds), Laboratory Animal Medicine. Academic Press, New York.

Jacobson E.R., Gaskin J.M. \& Brown M.B. 1991. Chronic upper respiratory tract disease of free-ranging desert tortoises (Xerobates agassizii). J. Wildl. Dis. 27(2):296-316.

Latimer K. \& Bienzle D. 2000. Determination and interpretation of the avian leukogram, p.417-432. In: Feldman B.F., Zinkl J.G. \& Jain N.C. (Eds), Schalm's Veterinary Hematology. $5^{\text {th }}$ ed. Lippincott Williams and Wilkins, Philadelphia. 1344p.

Lorenzi T.F., D’Amico E., Daniel M.M. \& Silveira P.A.A. 2003. Manual de Hematologia, Propedêutica e Clínica. $3^{\text {rd }}$ ed. Guanabara Koogan, Rio de Janeiro. 655p.

Mader D.R. 2000. Normal hematology of reptiles, p.1126-1132. In.: Feldman B.F., Zinkl J.G. \& Jain N.C. (Eds), Schalm's Veterinary Hematology. $5^{\text {th }}$ ed. Lippincott Williams and Wilkins, Philadelphia. 1344p.

Marcus L.C., Stottmeier K.D. \& Morrow R.H. 1975. Experimental infection of anole lizards (Anolis carolinensis) with Mycobacterium ulcerans by the subcutaneous route. Am. J. Trop. Med. Hyg. 24(4):649-655.

Mateo M.R., Roberts E.D. \& Enright F.M. 1984a. Inflammation induced by subcutaneous turpentine inoculation of young American alligators (Alligator mississippiensis). Am. J. Vet. Res. 45(9):1870-1875.

Mateo M.R., Roberts E.D. \& Enright F.M. 1984b. Morphologic, cytochemical and functional studies of peripheral blood cells of young healthy American alligators (Alligator mississippiensis). Am. J. Vet. Res. 45:1046-1053.

Montali R.J. 1988. Comparative pathology of inflammation in righter vertebrates (Reptiles, birds and mammals). J. Comp. Pathol. 99:1-26.

Natt M.P. \& Herrick C.A. 1952. A new blood diluent for counting the erythrocytes and leucocytes of the chicken. Poult. Sci. 31:735-738.

Nunes V.A. 2004. Estudo clínico-cirúrgico da imunoterapia com BCG (Bacilo de Calmette-Guérin) no tratamento adjuvante dos tumores 
mamários em cães (Canis familiaris). Dissertação de Mestrado, Faculdade de Medicina Veterinária, UFF, Niterói, RJ. 160p.

Raskin R.E. 2000. Reptilian Complete Blood Count, p.193-204. In: Fudge A.M. (Ed.), Laboratory Medicine: Avian and exotic pets. W.B. Saunders, Philadelphia. 486p.

Rodrigues L.M. 2000. Avaliação morfológica e citoquímica das células sanguíneas de serpentes dos gêneros Bothrops Wagler, 1824 e Crotalus Linnaeus, 1758. Dissertação de Mestrado, Faculdade de Medicina Veterinária, Universidade Federal Fluminense, Niterói, RJ. 82p.

Rosskopf W.J. Jr 2000. Disorders of reptilian leukocytes and erythrocytes, p.198-204. In: Fudge A.M. (Ed.), Laboratory Medicine: Avian and exotic pets. W.B. Saunders, Philadelphia. 486p.

Russell K.E. \& Grindem C.B. 2000. Secondary thrombocytopenia, p.487495. In: Feldman B.F., Zinkl J.G. \& Jain N.C. (Eds), Schalm's Veterinary Hematology. $5^{\text {th }}$ ed. Lippincott Williams and Wilkins, Philadelphia. 1344p.

Sado R.Y. \& Matushima E.R. 2008. Histopathological, immunohistochemical and ultraestructural evaluation of inflammatory response in Arius genus fish under experimental inoculation of BCG. Braz. Arch. Biol. Technol. 51(5):929-935.

Saint Girons M.C. 1970. Morphology of the circulating blood cells, p.7392. In: Gans C. (Ed.), Biology of Reptilia: Morphology. Vol.3. Academic Press, New York.
Smith D.A. \& Barker I.K. 1988. Healing of cutaneous wounds in the common garter snake (Thamnophis sirtalis). Can. J. Vet. Res. 52(1):111-119.

Smith D.A., Barker I.K. \& Allen O.B. 1988a. The effect of ambient temperature and type of wound on healing of cutaneous wounds in the common garter snake (Thamnophis sirtalis). Can. J. Vet. Res. 52(1):120-128.

Smith D.A., Barker I.K. \& Allen O.B. 1988b. The effect of certain topical medications on healing of cutaneous wounds in the common garter snake (Thamnophis sirtalis). Can. J. Vet. Res. 52(1):129-133.

Smith G.S. 2000. Neutrophils, p.281-296. In: Feldman B.F., Zinkl J.G. \& Jain N.C. (Eds), Schalm's Veterinary Hematology. $5^{\text {th }}$ ed. Lippincott Williams and Wilkins, Philadelphia. 1344p.

Stockham S.L. 2000. Hematologic changes due to bacterial infections, p.38-43. In: Feldman B.F., Zinkl J.G. \& Jain N.C. (Eds), Schalm's Veterinary Hematology. $5^{\text {th }}$ ed. Lippincott Williams and Wilkins, Philadelphia. 1344p.

Troiano J.C., Vidal J.C., Gould J. \& Gould E. 1997. Haematological reference intervals of the South American rattlesnake (Crotalus durissus terrificus, Laurent, 1768) in captivity. Comp. Hematol. Int. 1:109-112.

Tucunduva M., Borelli P. \& Silva J.R.M.C. 2001. Experimental Study of induced inflammation in the Brazilian boa (Boa constrictor constrictor). J. Comp. Pathol. 125(2-3):174-181. 